\title{
Design and Development of Experimental Hardware in Loop Model for the Study of Vibration Induced in Tall Structure with Active Control
}

\author{
Nauman Bashir ${ }^{1 *}$, Mohsin Jamil', Asim Waris ${ }^{1,2}$, Muhammad Nasir Khan'1, Mazhar Hussain Malik ${ }^{3}$ \\ and Shahid Ikramullah Butt ${ }^{1}$ \\ 'National University of Sciences and Technology, Islamabad, Pakistan; 14msmenbashir@smme.edu.pk, mohsin@ \\ smme.nust.edu.pk, aw@hst.aau.dk \\ dr.nasirkhan@ucp.edu.pk,drshahid@smme.nust.edu.pk \\ ${ }^{2}$ Aalborg University, Aalborg, Denmark \\ ${ }^{3}$ Institute of Southern Punjab, Multan, Pakistan; mazhar.hussain@isp.edu.pk
}

\begin{abstract}
Background/Objectives: This paper focuses on the active control of vibration in tall structure prone to high winds and earthquakes using the active mass dampers. Methods/Statistical Analysis: The prototype model was fabricated to measure the response of external forces and control methods have been implemented to minimize the damping. Modeling of servomotor and tall structure was studied theoretically and experimentally in view of controlling the angular velocity and position of the servomotor while displacement for the tall structure. Findings: PID controller was implemented on the structure for effective damping of the vibration which was easy in computation and cost effective. Application/ Improvements: The proposed study is very useful for practical implementations in small scale industries.
\end{abstract}

Keywords: Active Control, Active Mass Dampers, Structure Vibration

\section{Introduction}

Trends in construction have been advanced toward tall structure, high rise buildings and long span bridges which are prominent solution for densely populated areas ${ }^{1}$. Although the advancements in construction methods have led to more optimal solutions and high strength material but these lighter structures are more exposed to vibrations, which is threat to human life and can cause human discomfort, damages, and ultimately structural failure. A large amount of deflection and acceleration is observed in the structures because of the ineffective damping provided by the building itself when subjected to external loads.

During 1950's damping system was introduced to the mechanical industry and experimentation. Its first application dates back to 1969 with World Trade Centre. To minimize vibration in tall buildings effective damping techniques have been implemented specifically active, passive and hybrid dampers ${ }^{2}$ differentiating in mechanism. Active systems are robust and effective to variation and uncertainties on the modal parameter of structure. This system adapts to variable loading conditions and apply necessary control measures in real-time. Active system is governed by (1) accelerometer and sensors which measure the structures response; (2) controller to determine an appropriate angular velocity and position for the servomotor and mass to damp out vibrations; and (3) electromechanical actuators producing the requisite amount of inertial effect. Various control approaches have been used for active system like linear methods, including output feedback control utilizing acceleration feedback. Moreover nonlinear methods are also the part of it including neural methods ${ }^{3}$, fuzzy-logic based methods ${ }^{4}$, genetic

${ }^{*}$ Author for correspondence 
algorithms $s^{5}$ and adaptive methods ${ }^{6}$. Active control system uses the techniques of active bracing system ${ }^{7}$ and active mass dampers. On the other hand Passive control ${ }^{8}$ system counters the vibration in building by inertial force generated by the mass and these systems have fixed properties and do not require external source due to which these are economical but inefficient further categorized into Tuned Mass Liquid Dampers (TLMD) and Tuned Mass Dampers (TMD), these dampers were implemented to control the civil structure vibration 1970's and 1980s.

Utilization of active system in conjunction with passive system yields hybrid control systems. ${ }^{9}$. Hybrid controls are capable to limits the drawbacks of each system operating independently. In this system control force is delivered by passive controls while activating the active control system with less force and power requirement due to which there is less chance of instability. By improving the shortcomings of both systems, good results are achieved, though the system becomes complex classifying them as hybrid dampers ${ }^{10}$ and base isolation system ${ }^{11}$ as compared to independent system. Hybrid mass damper constitutes of passive control tuned-mass damper with active control electromechanical actuators. In base isolation passive base isolation are combined with hydraulic systems to minimize the displacement and acceleration. In this way normally passive system are capable of adapting the variable loading conditions and are cost effective when used with active systems. Active control system using classical controller specifically the PID Controller ${ }^{12}$ are applied to servomotor and tall structure to have better control for the induced vibration making the structure reliable and safe for human life when excited by winds and earthquakes.

\section{Mathematical Modeling}

\subsection{Servomotor}

Dynamics of servomotor are interpreted from its mathematical model. For that two controls have been taken into account namely position and velocity for the servomotor. This mathematical model is implemented in MATLAB/ Simulink to observe its behavior. To model the dc motor coupled with load, relationship of output to input is as stated as follows,

$$
\mathrm{V}_{\mathrm{S}}=\mathrm{V}_{\mathrm{R}}+\mathrm{V}_{\mathrm{L}}+\mathrm{V}_{\mathrm{B}}
$$

$$
v_{B}=k_{B} \omega
$$

where $\mathrm{V}_{\mathrm{S}}$ source voltage, $\mathrm{V}_{\mathrm{R}}$ is the voltage across the resistor, $V_{L}$ is the voltage across the inductor and $\mathrm{V}_{\mathrm{B}}$ is the back electromagnetic force (emf) voltage.

$$
\begin{aligned}
& \overline{d t} \quad \frac{i(t)}{I} \\
& \frac{d i(t)}{d t}=\frac{1}{L}\left(V_{s} E i(t)-K_{B} \omega(t)\right)
\end{aligned}
$$

where $\mathrm{V}_{\mathrm{s}}$ source voltage which acts as input to motor and $\mathrm{u}(\mathrm{t})$ the angular velocity is the output of the system. Essential parameter of motor includes,

$\mathrm{R}$ = represents the winding resistance.

$\mathrm{K}_{\mathrm{B}}=$ represents the constant for back emf.

$\mathrm{K}_{\mathrm{T}}=$ the torque constant.

$\mathrm{L}=$ the inductance.

$\mathrm{I}_{\mathrm{L}}=$ the moment of inertia.

\subsection{Tall Structure}

The prototype model is developed for the measurements of parameter for tall structure and buildings when subjected to external forces which dampens the effects by the help of controllers as it is expensive and impossible to develop a complex dynamic model of tall structure whose parameter can have relatively large tolerances. An alternative is adopted by fabricating a structure of $1 \mathrm{~m}$ in height using the stainless steel rod $10 \mathrm{~mm}$ in diameter fixed with the base of workbench with attached frame at a height of $1 \mathrm{~m}$ for supporting servomotor to dampen the either random vibration or deterministic vibration induced into the model structure ${ }^{13}$. For the damping of aerodynamic effects a plate is attached at middle of the rods which may be used to measure the wind effects and parameters. Responses for the structure against external forces are measured using the accelerometer fixed with the base frame of servomotor at the top. The active mass damper consisting of mass coupled with the rotating shaft of servomotor comes into action to cope with the effect of responses and minimizes the vibration effect by moving the mass out of phase with the structure's vibration. The 
dynamics for tall structure subjected to external forces is provided by the second order equation as ${ }^{14}$

$$
\mathrm{M} \ddot{\mathrm{X}}(\mathrm{t})+\mathrm{C} \dot{\mathrm{X}}(\mathrm{t})+\mathrm{Kx}(\mathrm{t})=\mathrm{F}(\mathrm{t})
$$

where $\mathrm{F}$ denote the excitation force input to the system by earthquake or wind, $\mathrm{M}$ is the mass, $\mathrm{K}$ is the Stiffness, $\mathrm{C}$ represents the damping constant and $\mathrm{X}$ is the displacement that is to be controlled.

\section{Controller Design}

Dynamics system states can be controlled by closed loop controller with feedback. With variation in process inputs (e.g. voltage), outputs (e.g. position or velocity and displacement) are affected. Feedback strategy is applied using the excitation produced and displacement measured by accelerometer while providing the necessary control to the structure using Proportional Integral Derivative (PID) controller to damp out the disturbances induced by the external excitations. The controller minimizes the error signal thereby minimizing the value of displacement of the structure in lateral direction using the actuator and active mass dampers by moving it out of phase with the structure vibrations. Gains for PID controller and transfer function for the tall structure are as expressed as follow

$$
\begin{aligned}
& U(t)=K_{P} e(t)+K_{I} \int e(t) d t+K_{D} \frac{d e}{d t} \\
& \frac{X(t)}{F(t)}=\frac{1}{M s^{2}+B S+K}
\end{aligned}
$$

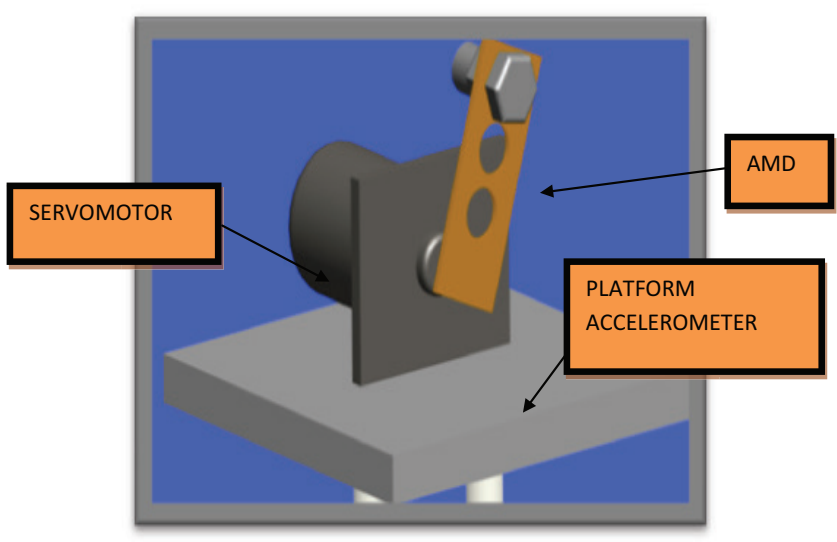

Figure 1. PTC Creo Model for Servo Motor with AMD.

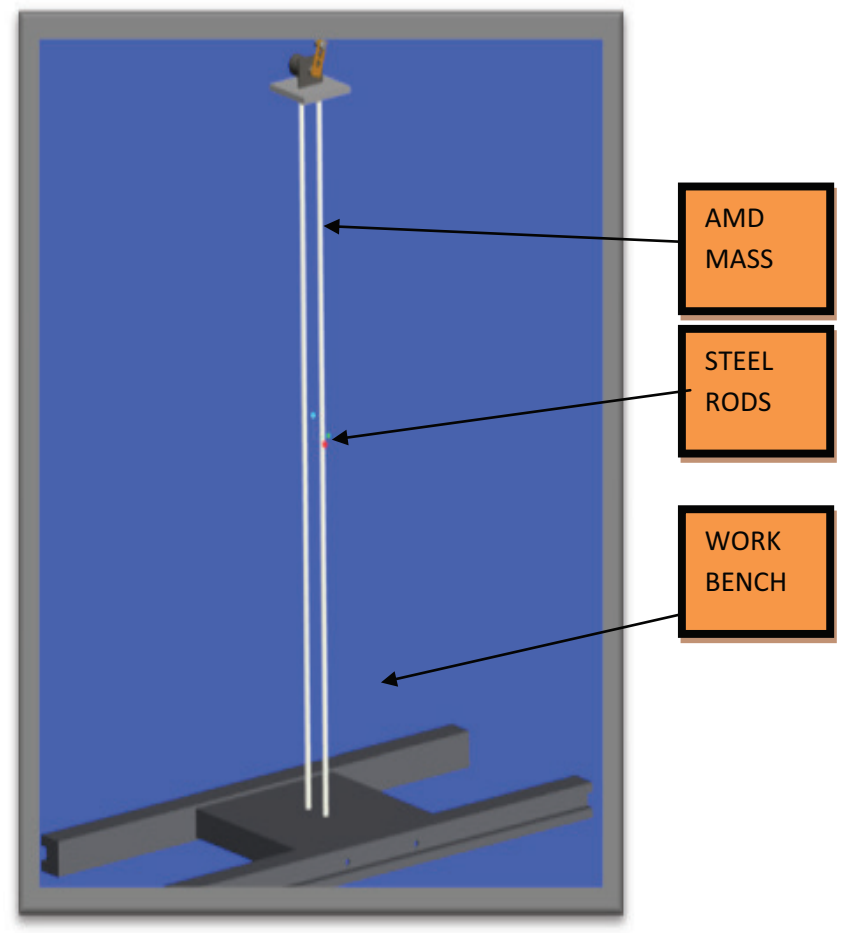

Figure 2. PTC CreoModel for Tall Structure.

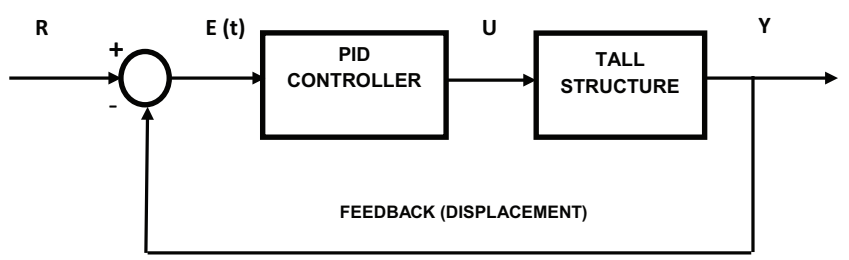

Figure 3. Block Diagram for PID Controller.

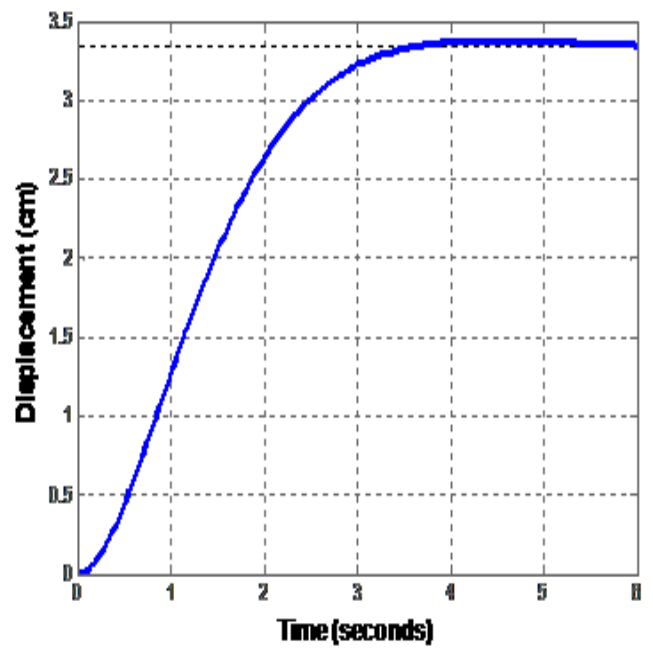

Figure 4. Open Loop Response without Controller. 


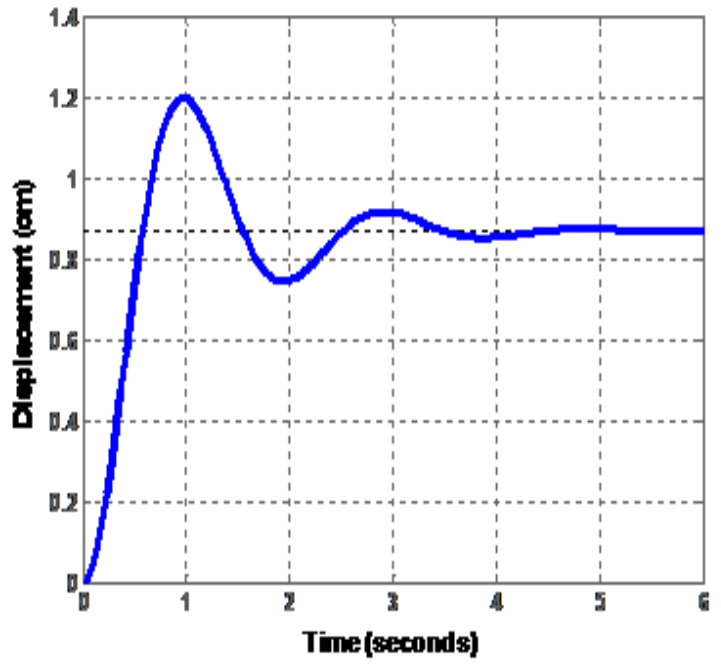

Figure 5. Closed Loop Response with $\mathrm{K}_{\mathrm{p}}=2$.

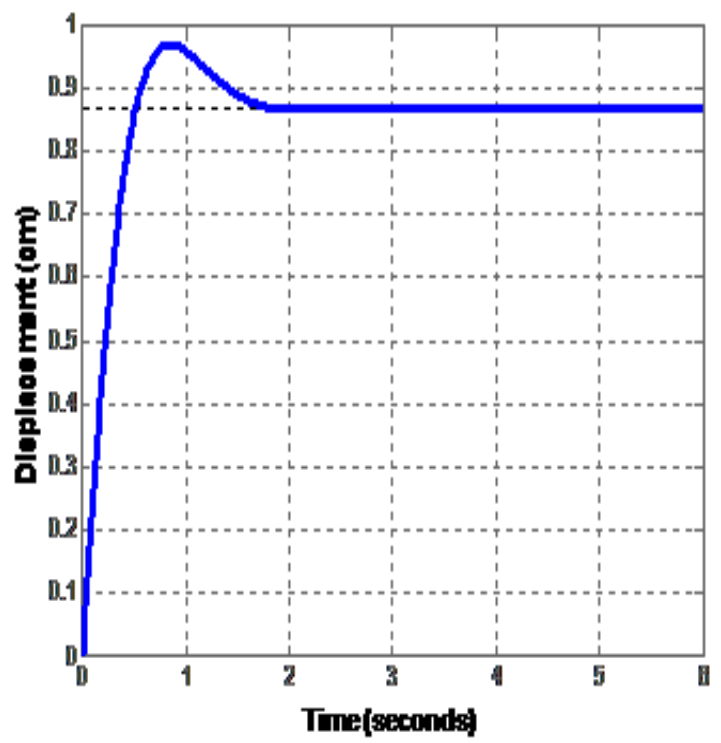

Figure 6. Closed Loop Response with $\mathbf{K}_{\mathbf{P}}=2 \& \mathbf{K}_{\mathbf{D}}=0.5$.

The mass $\mathrm{M}$ is considered to be $0.2 \mathrm{~kg}$, damping constant B is taken as $0.4 \mathrm{~N} . \mathrm{s} / \mathrm{m}$ and stiffness $\mathrm{K}$ is taken as $0.3 \mathrm{~N} / \mathrm{m}$ with excitation force of $1 \mathrm{~N}$. Against these values results are generated by implementing the PID controller on the plant model. The notation $\mathrm{R}$ is the reference signal, $\mathrm{Y}$ is the output, $\mathrm{U}$ is the control signal generated by the PID controller. E ( $t$ ) is the error signal fed after the summation of feedback from the output and reference signal.

\section{Results}

The open loop response for the tall structure without the effects of PID controller is as plotted in Figure 4 with rise

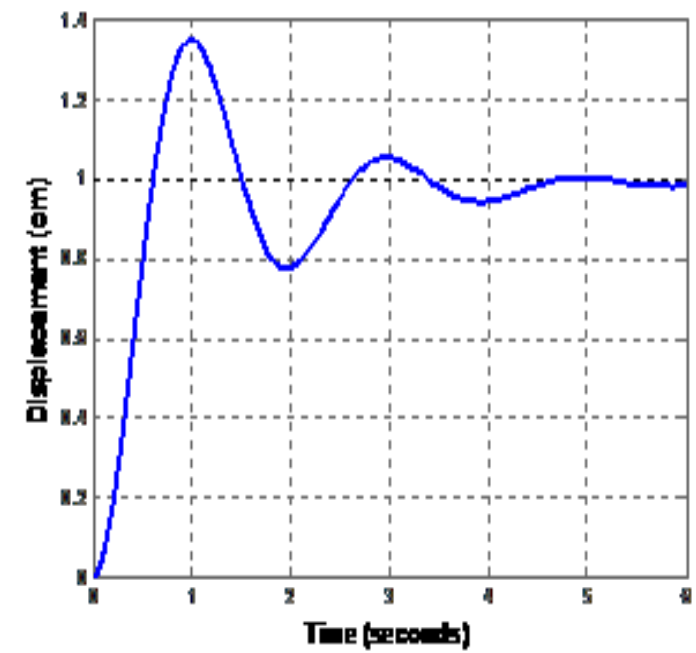

Figure 7. Closed Loop Response with $\mathbf{K}_{\mathbf{P}}=2$ \& $\mathbf{K}_{\mathbf{I}}=0.8$.

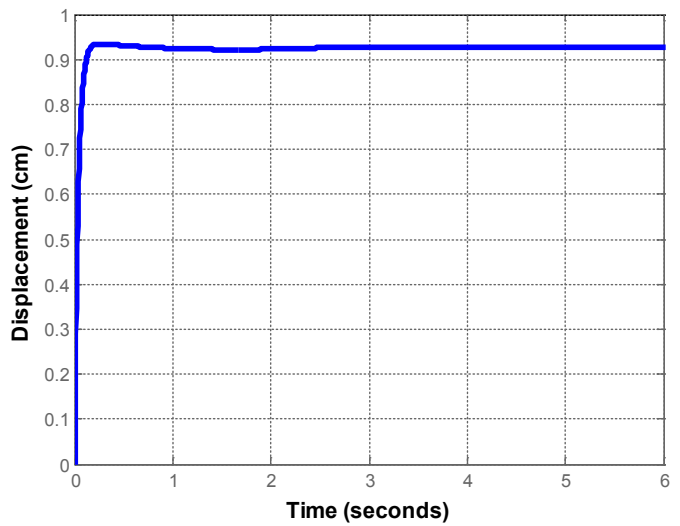

Figure 8. Closed Loop response with $\mathbf{K}_{\mathbf{P}}=2, \mathbf{K}_{\mathbf{I}}=0.8 \& \mathbf{K}_{\mathbf{D}}$ $=5$.

time of $2.07 \mathrm{sec}$, settling time of $3.18 \mathrm{sec}$, overshoot of $1.18 \%$ with maximum displacement of $3.37 \mathrm{~cm}$ and steady state of $3.33 \mathrm{sec}$. The closed loop response for the tall structure with $\mathrm{P}$ controller is as plotted in Figure 5 with rise time decreased to $0.4 \mathrm{sec}$, overshoot of $37 \%$, settling time of $3.96 \mathrm{sec}$ and steady state of $0.87 \mathrm{sec}$. The closed loop response for the tall structure with PD controller is as plotted in Figure 6 with rise time decreased to 0.389 sec, overshoot of $11.2 \%$, settling time of $1.51 \mathrm{sec}$ and steady state of $0.87 \mathrm{sec}$.

The closed loop response for the tall structure with PI controller is as plotted in Figure 7 with parameters values rise time of $0.411 \mathrm{sec}$, overshoot of $34 \%$, and eliminates the steady state error. The closed loop response for the tall structure with PID controller is as plotted in Figure 8 with no overshoot, fastest rise time of $0.116 \mathrm{sec}$ and no steady state error. 


\section{Conclusion}

The suppression of vibrations in the tall structure was studied with help of prototype, modelled in PTC Creo and fabricated from stainless steel fixed with servomotor and accelerometers. Fast transient response and zero steady state error were achieved with PID controller in MATLAB/Simulink. Active control was implemented on single degree of freedom structure having two support columns which in future may be applied on multi- degree of freedom with four columns. In future other advance controllers like state space, pole placement controllers can be implemented on the structure.

\section{References}

1. Ali MM, Moon KS. Structural Developments in Tall Buildings: Current Trends and Future Prospects. Architectural Science Review. 2007; 50(3):205-23.

2. Seto K. Large Scale Structures and Their Vibration Problems. Journal of System Design and Dynamics. 2007; 1(2):105-19.

3. Yoshida O, Dyke S. Seismic control of a nonlinear benchmark building using smart dampers. Journal of Engineering Mechanics. 2004;130(4):386-92.

4. Aldawod $\mathrm{M}$ et al. Active control of along wind response of tall building using a fuzzy controller. Engineering Structures. 2001; 23(11):1512-22.

5. Pourzeynali S, Lavasani HH, Modarayi AH. Active control of high rise building structures using fuzzy logic and genetic algorithms. Engineering Structures. 2007; 29(3):346-57.

6. Safak E. Adaptive Modeling, Identification, and control of dynamic structural Systems. I: Theory. Journal of Engineering Mechanics. 1989; 115(11):2386-405.
7. Kwok KCS, Samali B. Performance of tuned mass dampers under wind loads. Engineering Structures. 1995; 17(9):655-67.

8. Ricciardelli F, Pizzimenti AD, Mattei M. Passive and active mass damper control of the response of tall buildings to wind gustiness. Engineering Structures. 2003; 25(9):1199209.

9. Lei Y, Wu D-T, Lin S-Z. Integration of decentralized structural control and the identification of unknown inputs for tall shear building models under unknown earthquake excitation. Engineering Structures. 2013; 52(9):306-16.

10. Love JS, Tait MJ, Toopchi-Nezhad H. A hybrid structural control system using a tuned liquid damper to reduce the wind induced motion of a base isolated structure. Engineering Structures. 2011; 33(3):738-46.

11. Bahar A. Hierarchical semi-active control of base-isolated structures using a new inverse model of magnetorheological dampers. Computers and Structures. 2010; 88(7-8):483-96.

12. Guclu R. Sliding mode and PID control of a structural system against earthquake. Mathematical and Computer Modelling. 2006; 44(1-2):210-7.

13. Jamil M, Sharkh SM, Nasir M, Javid, Nagendra. Active control of vibrations of a tall structure excited by external forces. 6th International Bhurban Conference on Applied Sciences and Technology (IBCAST), Islamabad, Pakistan. 2009 Jan. p. 05-08.

14. Jamil M. Modelling and Identification for Active Control of Tall Structure Excited By External Forces. Proceeding of 13th IEEE/IFAC Conference on Methods and Models in Automation and Robotics, Poland. 2007 Mar. p. 1-5. 